\title{
Artificial intelligence in developing countries
}

By: Nir Kshetri

Kshetri, Nir (2020)."Artificial intelligence in developing countries" IEEE IT Professional, 22(4) 63 - 68. https://doi.org/10.1109/MITP.2019.2951851

(C) 2020 IEEE. Personal use of this material is permitted. Permission from IEEE must be obtained for all other uses, in any current or future media, including reprinting/republishing this material for advertising or promotional purposes, creating new collective works, for resale or redistribution to servers or lists, or reuse of any copyrighted component of this work in other works.

\section{Abstract:}

Al applications are tackling economic and social challenges facing developing countries. Economically speaking, Al possesses unique mechanisms that allow it to have significant impacts on economic productivity. While developing countries may experience a decline in outsourcing jobs from developed countries, the potential negative impact of such decline can be minimized by appropriate policy to deploy Al solutions. The true potential of Al comes from the ability to complement as well as enhance traditional factors of production.

Keywords: artificial intelligence $\mid$ macroeconomics $\mid$ job outsourcing | economic productivity | AI applications | developing countries | agriculture

\section{Article:}

Artificial intelligence (AI) applications are being used to improve economic, social, and environmental performance in developing economies. AI applications in these economies already do some tasks faster and better than humans. For instance, China's Ant Financial's AIbased chatbot system outperforms humans in delivering customer satisfaction. ${ }^{1}$

Other applications perform activities that human beings or other technologies are not capable of doing. An autonomous four-wheeled robot developed by Peru's National Engineering University explores mines to detect dangerous substances such as methane, carbon dioxide, and ammonium. It collects information about their levels and trends. Using sensors, it detects location and generates actions to be taken such as the best routes for the workers to escape (http://www.andina.com.pe/Agencia/noticia-robot-minero-tambien-tendria-utilidad-agriculturay-desastres-naturales-621069.aspx).

AI is arguably the fundamental technology of the Fourth Industrial Revolution (4IR). ${ }^{2}$ Unsurprisingly many developing countries have made serious commitment to develop AI capabilities. They are accelerating the process of establishing new policies, regulations, and practices for utilizing AI. Countries such as China, India, Kenya, Mexico, Russia, and the UAE have released AI strategy documents (https://www.strategy-business.com/blog/Is-AI-the-NextFrontier-for-National-Competitive-Advantage?gko=931c6). Others have developed broader 
visions to transform their economies using 4IR technologies (https://www.iol.co.za/businessreport/economy/wef-africa-botswana-tells-the-world-it-wants-to-reduce-dependence-ondiamonds-31998283).

There is, however, a wide variation among developing countries in the development of the AI industry. China is a clear global leader. Most other countries perform poorly in the main ingredients needed for building high-quality AI applications such as big data, computing power and manpower. Nonetheless, the AI ecosystem is gradually emerging in these countries.

\section{SOME NOTABLE AI APPLICATIONS LAUNCHED IN DEVELOPING COUNTRIES}

Table 1 provides illustrative examples of how AI is being used in diverse economic sectors.

Table 1. AI Use in Diverse Industries in Developing Economies

\begin{tabular}{|c|c|c|c|}
\hline $\begin{array}{l}\text { Sector/industry/ } \\
\text { activities }\end{array}$ & Company/app & Use of AI & Outcome \\
\hline $\begin{array}{l}\text { Farming and } \\
\text { agriculture }\end{array}$ & $\begin{array}{l}\text { Brazil's Solinftec's } \\
\text { AI assistant } \\
\text { Alice }\end{array}$ & $\begin{array}{l}\text { Integrates and processes data from machines, } \\
\text { people, network of climate stations, and other } \\
\text { sources }\end{array}$ & $\begin{array}{l}\text { Provides real-time } \\
\text { actionable } \\
\text { recommendations }\end{array}$ \\
\hline $\begin{array}{l}\text { Mining and } \\
\text { energy }\end{array}$ & Chile's Codelco & $\begin{array}{l}\text { Monitor mining equipment to predict maintenance } \\
\text { needs, detect anomalies and help prevent } \\
\text { problems }\end{array}$ & $\begin{array}{c}\text { Efficiency in } \\
\text { operations. }\end{array}$ \\
\hline Transportation & China's Didi & Predict traffic jams & $\begin{array}{c}\text { Minimize the impact of } \\
\text { traffic congestions }\end{array}$ \\
\hline $\begin{array}{l}\text { Healthcare and } \\
\text { medical }\end{array}$ & Nigeria's RxAll & Assesses a drug's compound & $\begin{array}{l}\text { Used in many foreign } \\
\text { markets }\end{array}$ \\
\hline $\begin{array}{l}\text { Finance, banking } \\
\text { and insurance }\end{array}$ & $\begin{array}{c}\text { China's Ant } \\
\text { Financial }\end{array}$ & Uses deep-learning technology to detect fraud. & $\begin{array}{l}\text { Losses related to fraud: } \\
\text { one in } 1 \text { million. }\end{array}$ \\
\hline HRM & Chile's AIRA & $\begin{array}{l}\text { Publishes vacancy announcements, reads/ranks } \\
\text { résumés, uses psychometric tests, conducts video } \\
\text { interviews and measures performance of } \\
\text { applicants. }\end{array}$ & $\begin{array}{l}\text { Reduces time that } \\
\text { human recruiters } \\
\text { need to spend. }\end{array}$ \\
\hline
\end{tabular}

Farming and Agriculture

AI has gained popularity in farming and agricultural sectors. Especially large-scale agriculture firms use AI to improve the speed and accuracy of planting and crop management techniques. Brazil's sugar and ethanol producer Raízen has teamed up with the start-up Space Time Analytics to develop an AI-based solution to forecast the sugarcane harvest's size for one year in advance (https://www.weforum.org/agenda/2017/03/artificial-intelligence-could-help-reverselatin-america-s-economic-slowdown/).

AI-based apps are diffusing rapidly among smaller firms. The Brazilian startup Solinftec's AI assistant Alice integrates and processes data from machines, people, climate stations, and other sources (https://www.nanalyze.com/2019/08/brazil-agriculture-technology/). To use Alice, farmers embed smart black boxes in their machinery and deploy IoT devices in fields. Alice calculates farmers' needs and provides real-time recommendations 
(https://www.croplife.com/precision/growmark-teams-up-with-solinftec-to-increase-farmefficiency/).

The initial solution was developed for the sugarcane industry. It also offers solutions for other crops. As of August 2019, Solinftec was being used on more than 6.5 million hectares. It monitored 20000 pieces of equipment and managed 100000 active daily users (https://www.nanalyze.com/2019/08/brazil-agriculture-technology/). Solinftec has opened North American offices in West Lafayette, Indiana (https://www.precisionag.com/marketwatch/brazils-solinftec-sets-up-shop-in-the-u-s/). It is also expanding to other South American countries as well as in Russia and Ukraine (https://agfundernews.com/the-road-to-automatedagriculture-begins-in-brazil.html).

Mining and Energy

Chile's copper producer Codelco uses autonomous trucks at its mines. These vehicles reduce costs by operating for longer hours. They also reduce accidents (https://hgomezgroup.com/2018/06/13/mining-technology-where-it-is-and-where-it-is-going-inchile). It uses AI to monitor mining equipment to predict maintenance needs and make sure that operations run efficiently (https://www.mining-journal.com/innovation/news/1359598/codelcoto-deploy-ai-solution).

\section{Transportation}

China's mobile-based ride-sharing service Didi uses predictive algorithms in order to help predict traffic jams to minimize the impact of traffic congestions to drivers. ${ }^{3}$ The company claimed that by using past as well as real-time data, it can forecast demands 15 minutes in advance with an $85 \%$ accuracy level. This information is used to build predictive dispatching models and send vehicles earlier to areas with high degrees of congestion (https://technode.com/2017/08/28/threeinteresting-facts-just-learned-didis-big-data/).

\section{Healthcare and Medical}

Nigeria's RxAll's handheld scanner fights fake drugs. It assesses a drug's compound by connecting the device to cloud-based databases, which contain information related to what the drugs should contain. The information is sent back to the phone. The database is updated using AI. The app also shows which other neighborhoods tested the drug. This gives information related to bad suppliers. It has also been used in Myanmar. The company plans to enter into Ghana, Cambodia, and Kenya (https://www.theguardian.com/globaldevelopment/2019/jun/05/fake-medicine-makers-blockchain-artificial-intelligence).

Finance, Banking, and Insurance

China's Ant Financial uses big data and AI to manage credit risk and lower loan delinquency rates $^{3}$ and detect fraud. ${ }^{4}$ Banks in Latin America also use chatbots to provide customer services. A survey found that $83 \%$ of consumers of Brazilian financial service would trust banking advice 
entirely generated by a computer (https:/www.accenture.com/us-en/insight-financial-servicesdistribution-marketing-consumer-study).

Kenya's Kenindia Assurance plans to use AI to detect fraudulent motor insurance claims (https://www.kbc.co.ke/kenyan-insurers-utilizing-artificial-intelligence-to-curb-fraud-cases/). In addition to the industry's Integrated Motor Insurance Data System (IMIDS) through the Association of Kenya Insurers, it plans to establish a data center of customers' insurance history.

\section{Human Resources Management (HRM)}

The Chilean company AI recruitment assistant's (AIRA) system publishes vacancy announcements in recruitment websites. It reads and ranks the résumés and uses psychometric tests. It also conducts video interviews with applicants. An applicant's performance is measured with indicators related to emotion analytics. Factors such as attention levels and facial expressions are converted into numbers. After all these processes are completed, human recruiters conduct in-depth interviews with the highest-ranked candidates (https://www.accenture.com/ acnmedia/pdf-48/accenture-ai-south-america.pdfla=es-la).

\section{ECONOMIC EFFECTS OF AI}

Some have argued that AI will have a negative impact on developing nations' export-led growth model. AI and automation in developed countries will arguably lead to a decline in the outsourcing of manufacturing and other jobs (https://www.atlanticcouncil.org/wpcontent/uploads/2018/06/The-Global-Innovation-Sweepstakes.pdf).

However, by using AI in diverse industries, developing nations may compensate for such losses. Even more impressive, technology firms from developing countries such as Brazil, China, Nigeria, and Russia are selling AI solutions in foreign markets. Especially the entry of young AI firms such as Brazil's Solinftec into developed countries is an important trend can shape AI's global competitive landscape.

Regarding the economic growth mechanisms, traditionally economists viewed new technologies as economic growth drivers through effects on total factor productivity (TFP). The factors of production are capital (e.g., machines and buildings) and labor that drive economic growth. Broadly TFP is a function of technological, economic, and other factors. TFP measures how efficiently the factors of production are being used. Technologies of the past such as electricity and IT boosted productivity. For example, the World Bank Group's World Development Report 2016 found that the Internet and e-commerce increased TFP in Vietnam by $1.9 \%$ and 3.6\%, respectively, during 2007-2012.

The global professional services company Accenture argues that in addition to its role in driving TFP, AI also acts a new factor of production. Various uses of AI are discussed in the previous section to illustrate this possibility. First, AI functions as a new workforce by replicating labor activities at a higher scale and speed. AI performs tasks that humans cannot and learns faster. AIenabled robots and intelligent machines can also function as a physical capital. Unlike 
conventional forms of capital such as machines and buildings, AI's self-learning capabilities help improve over time.

Accenture has used case studies of Latin American countries to illustrate AI as a new factor of production. The company forecasts that Brazil's gross value added (GVA) in 2035 will be US\$3452 billion without AI. If AI's impact is limited to TFP, its projected GVA will be US $\$ 3526$ billion. When AI is viewed as a factor of production, the value will further increase to US\$3884 billion (https://www.accenture.com/_acnmedia/pdf-48/accenture-ai-southamerica.pdfla $=$ es-la).

\section{OPPORTUNITIES TO DEVELOP THE AI INDUSTRY}

There are a number of opportunities to develop AI applications in developing countries. First, local technology hubs are rapidly evolving in many developing countries, which are developing solutions to solve local problems. As of October 2019, Africa had 618 tech hubs, which provide foundations for the AI industry.

Countries such as Ethiopia have launched high-profile AI initiatives. Most of Ethiopia's more than 30 official universities and 130 polytechnics emphasize on technology. In 2012, the Ministry of Science and Technology established its own university and developed a US\$250 million technology park. ${ }^{5}$ The country's AI and robotics research company iCog has produced several apps (https://nationalinterest.org/blog/buzz/will-ai-cripple-or-leapfrog-developingnations-growth-8771). One such project involves developing software for AI tablets to distribute to children, which would help teach themselves coding, mathematics, and English. ${ }^{5}$

Second, some multinationals are taking advantage of various resources in developing countries to develop cutting edge AI solutions. Such activities are likely to create positive externalities and spillover effects of AI-related knowledge to the local economy. Unilever developed an autonomous forklift in Brazil and launched first in its manufacturing units in the country before any other markets (https://www.weforum.org/agenda/2017/03/artificial-intelligence-could-helpreverse-latin-america-s-economic-slowdown/).

A related point is that many developing countries are increasingly participating in the value chain of the global AI industry. One such area is data labeling. According to a $2018 \mathrm{McKinsey} \mathrm{report,}$ data labeling is the biggest obstacle to AI adoption. ${ }^{6}$ According to analyst firm Cognilytica, the third-party data labeling solutions market was US\$150 million in 2018, which will increase to more than US\$1 billion by $2023 .^{7}$

Big Western companies are taking major initiatives in order to perfect the ML training. The datalabeling industry employs hundreds of thousands of workers in developing countries such as Kenya, India, and the Philippines. Some examples of data-labeling include teaching self-driving cars, the meanings of road signs, or the difference between a child and a fox. The India- and U.S.-based data annotation company iMerit had 2200 employees in India to label data generated by manufacturing, medical imaging, autonomous driving, retail, insurance agriculture, and other industries. Its Kolkata operation employs 460 women to train computer vision algorithms used in 
autonomous vehicles and augmented reality systems for companies such as Amazon, Microsoft, eBay, and TripAdvisor. ${ }^{7}$

Nairobi, Kenya-based Samasource labels data for Walmart, Google, Microsoft, Glassdoor, Continental, and General Motors. It employs more than 2800 people. $^{7}$

Some economic sectors are highly digitized, which makes it easier to develop AI-based solutions. For instance, industries such as financial services, telecommunications, and retail in Africa have relatively large amounts of data (https:/www.cio.com/article/3431656/what-africasapproach-to-ai-can-teach-the-world.html). Likewise, banking and retail industries are expected to dominate AI expenditure in the Middle East (https:/www.thenational.ae/business/technology/aispending-to-grow-43-in-middle-east-and-africa-in-2019-1.917352).

The availability of data at more granular levels is important to develop better algorithms, which is especially critical in personalizing experiences for users. However, doing so might compromise users' privacy or data confidentiality (https:/www.accenture.com/_acnmedia/pdf48/accenture-ai-south-america.pdfla=es-la). Whereas ethical and data privacy issues act as a hindrance to the development of the AI industry, such issues are less of a concern in developing countries. For instance, due to China's almost nonexistent privacy controls, Chinese companies have easy access to the data of over one billion users. The large datasets help algorithms produce more accurate results and predictions (https://carnegieendowment.org/2019/01/22/we-need-toget-smart-about-how-governments-use-ai-pub-78179).

\section{BARRIERS FACING DEVELOPING COUNTRIES IN THE DEVELOPMENT OF AI}

Developing countries experience various barriers and challenges in the development of the AI industry and markets. First, limited datasets are available for AI projects and the available data are of questionable quality. Due to wrong, low quality and irrelevant data, many ICT projects targeted at the poor fail to deliver the benefits that are promised by the initiators of such projects. One example is the "Index-based" crop insurance programs that have been promoted widely among small-scale farmers. The payment to a policyholder relies on satellite images to detect if extreme weather has affected a given area. The area may cover up to 1000 farmers. However, Canada's International Development Research Centre found that the promised benefits have not materialized because the technology gathers data on wide areas. It provides general views about the effects of drought or floods but fails to accurately measure rainfall at a local level. There have been cases in which satellite data indicated that an area had sufficient rainfall but some farmers experienced crop loss due to microclimates. They were not offered insurance payouts. Some discontinued their insurance schemes (https://www.reuters.com/article/us-climate-changekenya-insurance/kenyan-farmers-snap-crops-with-phones-to-improve-insurance-payoutsidUSKBN1WQ0Q7).

Second, in a discussion of AI's impacts on developing countries, it is also important to discuss noneconomic costs such as the loss of privacy. Such concerns exist at various stages from data gathering to develop AI applications to the actual use of AI. For instance, AI in China is being developed without giving sufficient considerations to ethical issues. ${ }^{8}$ 
Some countries are using AI to build surveillance tools that might violate privacy laws and human rights. These concerns have been especially strongly voiced against countries that have used China-developed solutions. China has sold AI and facial recognition software in developing countries such as Serbia, Turkey, Russia, Ukraine, Azerbaijan, Angola, Laos, Kazakhstan, Kenya, Uganda (https:/www.scmp.com/news/world/europe/article/3033267/huaweis-facialrecognition-technology-causes-anxiety-serbi), Ecuador, Bolivian, and Peru (https://foreignpolicy.com/2018/08/09/ecuadors-all-seeing-eye-is-made-in-china/).

The Chinese company CloudWalk works with the Zimbabwean government to develop a facial recognition program. China described this as a "win-win" deal. Chinese AI companies can train ML algorithms on Africans to diversify their datasets and Zimbabwe gets access to use the latest technology to monitor its population. ${ }^{9}$ Especially, deployment of China-developed solutions in countries with poor track records on human rights is a concern.

Third, some developing countries are using AI solutions developed by foreign companies, which often perform poorly and have limited usability. A Russian company is reported to be selling face recognition technology in South Africa and Kenya. These systems have a low level of accuracy and precision in Africa. ${ }^{10}$

Other impediments include unsupportive regulatory and policy environments. Some countries have a history of cutting Internet connections to tackle problems as varied as cheating by students in exams and political unrest by activists. In June 2019, Ethiopia shut down the Internet for three days during national examinations to prevent students from cheating (https://www.bloomberg.com/news/articles/2019-06-13/exam-cheats-cited-in-three-day-internetshutdown-in-ethiopia). In January 2019, Zimbabwe disrupted Internet connectivity for a week due to concerns related to unrest in disputed elections (https://www.bloomberg.com/news/articles/2019-01-21/zimbabwe-lawyers-sue-mobileoperators-over-internet-shutdown).

\section{SUMMARY}

AI applications are tackling economic and social challenges facing developing countries. Economically speaking, AI possesses unique mechanisms that allow it to have significant impacts on economic productivity. While developing countries may experience a decline in outsourcing jobs from developed countries, the potential negative impact of such decline can be minimized by appropriate policy to deploy AI solutions. The true potential of AI comes from the ability to complement as well as enhance traditional factors of production.

AI development in developing countries depends on many factors, inter alia, technology entrepreneurship, knowledge and expertise, data availability, and government policy. The success of an AI project is heavily dependent on the quality of data and algorithms. Especially the lack of data availability is a big obstacle to develop good quality of AI systems. AI performance is influenced by the lower level of training in AI algorithms.

There are major differences between developing and developed countries in AI uses. Due to the lack of huge investments AI-enabled robots and intelligent machines may not be as relevant and 
important in most developing countries. The most valuable uses of AI would be in performing tasks that humans are not currently capable of doing such as detecting dangerous gas leaks in mines, dealing with traffic congestion, and providing real-time actionable recommendations to farmers.

\section{REFERENCES}

1. W. Knight, "Meet the Chinese finance giant that's secretly an AI company," MIT Tech. Rev., Jun.2017. [Online]. Available: https://www.technologyreview.com/s/608103/ant-financialchinas-giant-of-mobile-payments-is-rethinking-finance-with-ai/

2. C. Herweijer and D. Waughray, "Fourth industrial revolution for the earth harnessing artificial intelligence for the earth," $P W C$, Jan.2018. [Online]. Available: https://www.pwc.com/gx/en/sustainability/assets/ai-for-the-earth-jan-2018.pdf

3. S. Zoo, "What Africa can learn from China about data privacy," World Econ. Forum, Jun.2019. [Online]. Available: https://www.weforum.org/agenda/2019/06/what-africa-canlearn-from-china-about-data-privacy/

4. B. Perez and Z. Soo, "China a fast learner when it comes to artificial intelligence-powered fintech, experts say," South China Morning Post, Oct.2017. [Online]. Available: https:/www.scmp.com/tech/innovation/article/2117298/china-fast-learner-whenit-comes-artificial-intelligence-powered

5. C. Galbraith, "Artificial intelligence catches fire in Ethiopia," HuffPost, Dec.2017.

6. M. Chui, J. Manyika, and M. Miremadi, "What AI can and can't do (yet) for your business," McKinsey \& Company, New York, NY, USA, Jan.2018. [Online].

Available: https://www.mckinsey.com/business-functions/mckinsey-analytics/ourinsights/what-ai-can-and-cant-do-yet-for-your-business

7. M. Murgia, "AI's new workforce: The data-labelling industry spreads globally," Financial Times, Jul.2019. [Online]. Available: https:/www.ft.com/content/56dde36c-aa40-11e9-984cfac8325aaa04

8. D. Meyer, "A.I. regulation is coming soon. Here's what the future may hold," Fortune, Oct.2019. [Online]. Available: https://fortune.com/2019/10/24/german-eu-data-ethics-airegulation/

9. "Exporting repression? China's artificial intelligence push into Africa," Council Foreign Relations, Dec.2018. [Online]. Available: https://www.cfr.org/blog/exporting-repressionchinas-artificial-intelligence-push-africa

10. J. Snow, "How Africa is seizing an AI opportunity," Fast Company, Mar.2019. [Online]. Available: https://www.fastcompany.com/90308114/how-africa-is-seizing-an-ai-opportunity

Nir Kshetri is a professor of management in the Bryan School of Business and Economics, University of North Carolina at Greensboro, Greensboro, NC, USA. Contact him at nbkshetr@uncg.edu. 